\title{
Development of Microstructure and Mechanical Properties in Laser-FSW Hybrid Welded Inconel 600
}

\author{
Kuk Hyun Song*, Takuya Tsumura and Kazuhiro Nakata \\ Joining and Welding Research Institute, Osaka University, Ibaraki 567-0047, Japan
}

The present study was carried out to evaluate the microstructure and mechanical properties of Inconel 600 subjected to laser-assisted hybrid friction-stir welding (HFSW). In this process, friction-stir welding (FSW) was performed at a constant speed (400 rpm) while a 2-kW YAG laser preheated the material just in front of the rotating tool. We found that HFSW was 1.5 times faster than conventional FSW. In addition, analysis of the grain boundary character distribution by electron back scattered diffraction (EBSD) showed that the increased welding speed and dynamic grain recrystallization caused the average grain size to decrease from $5.5 \mu \mathrm{m}$ (in the base material) to $3.2 \mu \mathrm{m}$ (in the stir zone of the welded specimen). This grain refinement led to $30 \%$ and $10 \%$ improvements in microhardness and tensile strength, respectively. [doi:10.2320/matertrans.M2009058]

(Received February 17, 2009; Accepted April 13, 2009; Published June 17, 2009)

Keywords: Inconel 600, YAG laser, hybrid friction stir welding, electron back scattered diffraction, mechanical properties

\section{Introduction}

Ni-base superalloys are widely used to manufacture parts for power plants, gas turbines, and marine systems because of their excellent corrosion resistance, fatigue resistance, hightemperature strength, workability and weldability. ${ }^{1,2)}$ However, Ni-base superalloys are not compatible with traditional fusion welding techniques because the large heat input can cause $\mathrm{Cr}$ segregation at the grain boundaries, thereby causing material degradation such as hot cracking and corrosion. ${ }^{3,4)}$ Thus, the recommended alternative at present is friction-stir welding, which keeps the material in the solid state due to its lower heat input. ${ }^{5)}$ However, FSW of Ni-base superalloys which retain their strength at high temperature is much more difficult than that that of materials with lower melting points, such as $\mathrm{Al}$ and $\mathrm{Mg}$ alloys. ${ }^{5,6)}$ Increased tool wear occurs because of the high load between material and tool, and this also reduces the welding speed. These issues can be addressed by hybrid friction-stir welding (HFSW) techniques, wherein the downward load between tool and material is reduced by using an additional heat source such as TIG arc, plasma arc, or YAG laser beam.

Laser-assisted hybrid arc welding has attracted considerable attention because of its many advantages: deeper weld penetration, higher welding efficiency, and fewer weld defects. $^{7-10)}$ For these advantages, hybrid methods can be easily applied to welding process as couple of welding method, such as laser-arc, laser-TIG, laser-MIG and laserFSW. ${ }^{7-11)}$ A recent report showed that HFSW is faster than the conventional method for materials with high melting points, such as steels, because of the reduced downward force between material and tool. ${ }^{11)}$ However, to the best of our knowledge, the effects of HFSW on Ni-base superalloys have not been previously reported. Therefore, we carried out HFSW of Ni-base superalloys and evaluated the changes in the microstructure and mechanical properties with increasing welding speeds.

${ }^{*}$ Corresponding author, E-mail: song@jwri.osaka-u.ac.jp
Table 1 Chemical composition of Inconel 600 alloy.

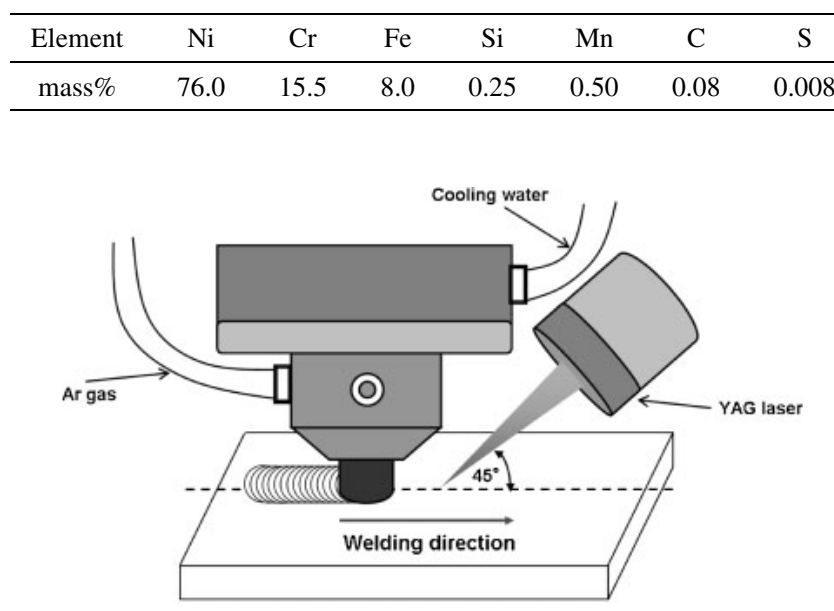

Fig. 1 Schematic diagram of hybrid friction stir welding.

\section{Experimental Procedure}

The material used in this study was Inconel 600, whose chemical composition is shown in Table 1. For HFSW, sheets of the material were prepared with the dimensions of $150 \mathrm{~mm} \times 75 \mathrm{~mm} \times 2 \mathrm{~mm}$. HFSW was carried out using a WC-Co tool with a shoulder of diameter $15 \mathrm{~mm}$ and a probe of diameter $6 \mathrm{~mm}$ and length $1.8 \mathrm{~mm}$. Furthermore, to achieve good weld quality, the tool was tilted $3^{\circ}$ forward from the vertical, and argon gas was used to prevent surface oxidation during welding. A $2-\mathrm{kW}$ YAG laser was the preheating source; the laser was incident on the material surface at an angle of $45^{\circ}$ forward from the vertical, as shown in Fig. 1. HFSW was performed under the following conditions: tool rotation speed, $400 \mathrm{rpm}$; downward force, $22.5 \times 10^{3} \sim 35.3 \times 10^{3} ;$ and traveling speed, 300 450 $\mathrm{mm} / \mathrm{min}$.

To observe the macrostructures and microstructures of the welded specimens, a solution composed of $97 \mathrm{~mL} \mathrm{HCl}, 2 \mathrm{~mL}$ $\mathrm{HNO}_{3}$ and $1 \mathrm{~mL} \mathrm{H}_{2} \mathrm{SO}_{4}$ was prepared, and the surfaces of the samples were etched with this solution after polishing them with abrasive paper. Electron back scattered diffraction 
(a)

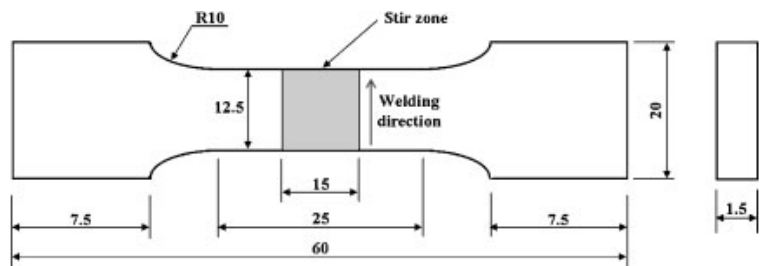

(b)

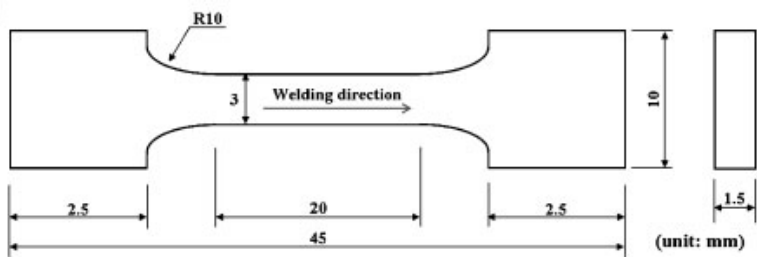

Fig. 2 Specifications of (a) transverse (weld joint) and (b) longitudinal (stir zone) specimens used in the present study.
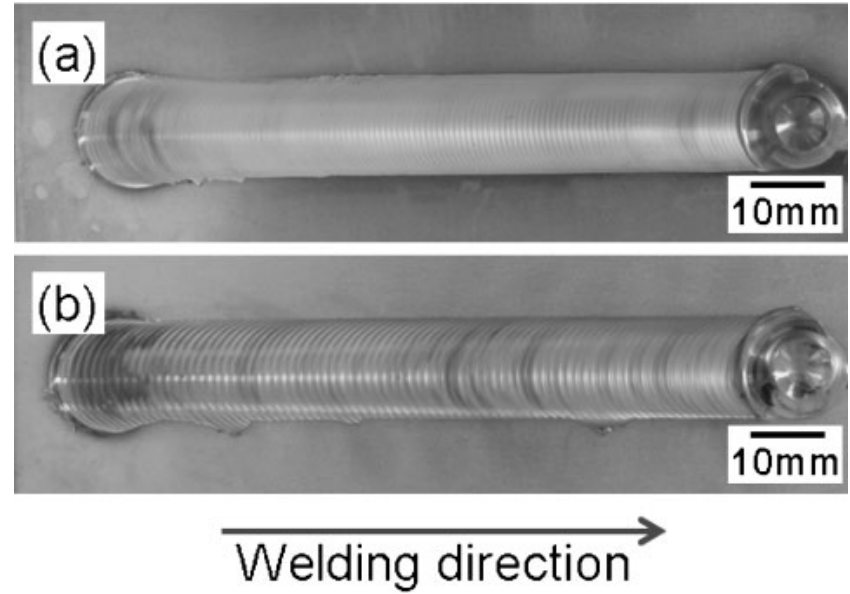

Fig. 3 Welding profiles of the specimens welded at a welding speed of (a) $300 \mathrm{~mm} / \mathrm{min}$ and (b) $450 \mathrm{~mm} / \mathrm{min}$.
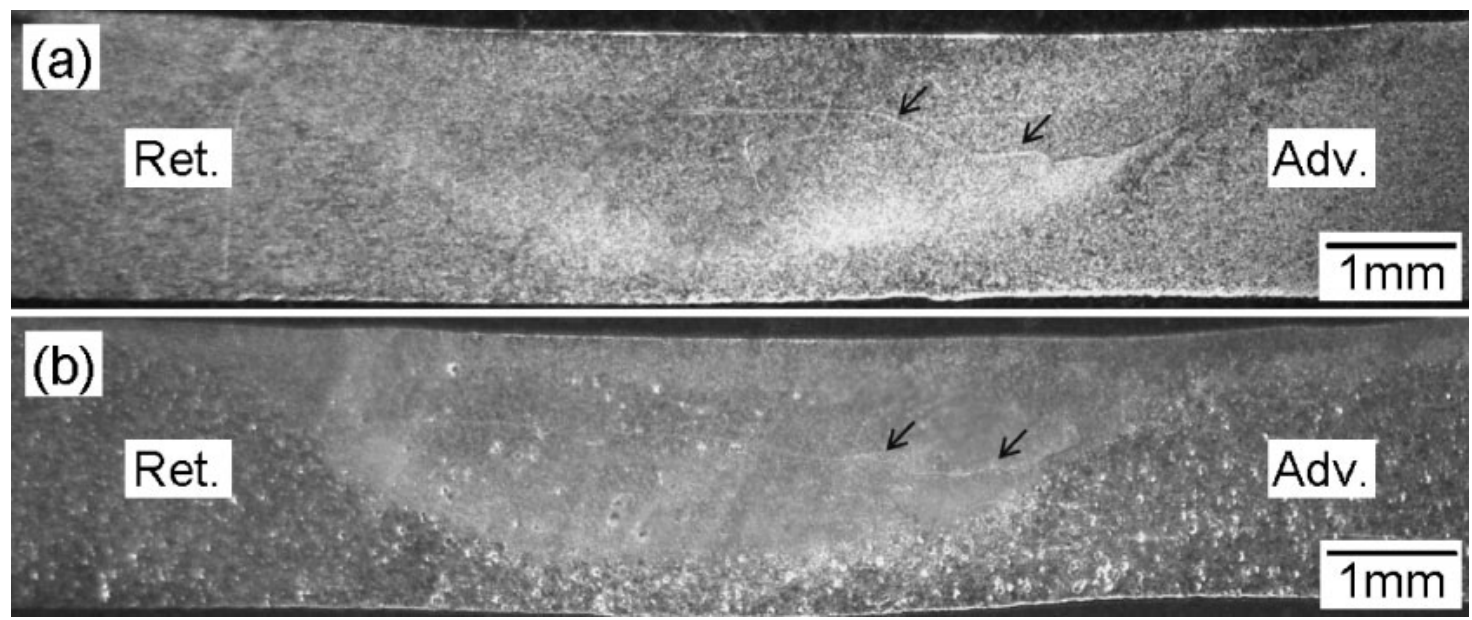

Fig. 4 Macrostructures of the weld zone in the specimens welded at a welding speed of (a) $300 \mathrm{~mm} / \mathrm{min}$ and (b) $450 \mathrm{~mm} / \mathrm{min}$. Adv. and Ret. indicate the advancing side and retreating side, respectively, of the weld. Arrows indicate the presence of the band structure in the stir zone.

(EBSD) was then employed to evaluate the grain size and grain boundary character distribution (GBCD) in the base material and the stir zone. The samples were prepared for analysis by polishing them by using a Vibromet after mechanical polishing. EBSD analysis of the weld zone was carried out by using TSL-OIM ${ }^{\mathrm{TM}}$ incorporated with SEM.

In order to evaluate the mechanical properties, a Vickers microhardness test and tensile test were carried out. The Vickers hardness test was carried out along the cross section of the weld zone using a load of $9.8 \mathrm{~N}$ and a dwell time of $15 \mathrm{~s}$. Two types of tensile test specimens were used in the tensile tests to evaluate the transverse tensile strength of the welds and the longitudinal tensile strength of the stir zone, as shown in Fig. 2.

\section{Results}

The weld profile of a hybrid friction-stir welded Inconel 600 sheet is shown in Fig. 3. At welding speeds of 300 and $450 \mathrm{~mm} / \mathrm{min}$, the specimens were perfectly welded without causing any surface defects, as shown in Fig. 3. The macrostructures of samples welded at speeds of 300 and
$450 \mathrm{~mm} / \mathrm{min}$ are shown in Fig. 4. At $300 \mathrm{~mm} / \mathrm{min}$, the weld penetrated $1.9 \mathrm{~mm}$ into the specimen without introducing any defects in the stir zone; however, a band structure was observed at the center of the stir zone, as shown in Fig. 4(a). At $450 \mathrm{~mm} / \mathrm{min}$, the penetration depth was lower, but a similar band structure was still observed at the center of the stir zone, as shown in Fig. 4(b).

The temperature hysteresis of the stir zone at the two welding speeds at a constant rotation rate is shown in Fig. 5. Measurements for temperature hysteresis were carried out at the center of the weld zone along the bottom surface of the plate during the HFSW. At $300 \mathrm{~mm} / \mathrm{min}$, the maximum temperature in the stir zone was $810^{\circ} \mathrm{C}$, as shown in Fig. 5, and at $450 \mathrm{~mm} / \mathrm{min}$, the maximum temperature in the stir zone was observed to be $845^{\circ} \mathrm{C}$. This increase in maximum temperature at $450 \mathrm{~mm} / \mathrm{min}$ can be explained by the higher downward force exerted by the tool $\left(35.3 \times 10^{3} \mathrm{~N}\right)$ when compared to that exerted by the tool at $300 \mathrm{~mm} / \mathrm{min}$ $\left(22.5 \times 10^{3} \mathrm{~N}\right)$. Furthermore, this increase in the welding speed led to an increase in the relative cooling rate; thus, the sample welded at $450 \mathrm{~mm} / \mathrm{min}$ cooled more rapidly than that welded at $300 \mathrm{~mm} / \mathrm{min}$. 


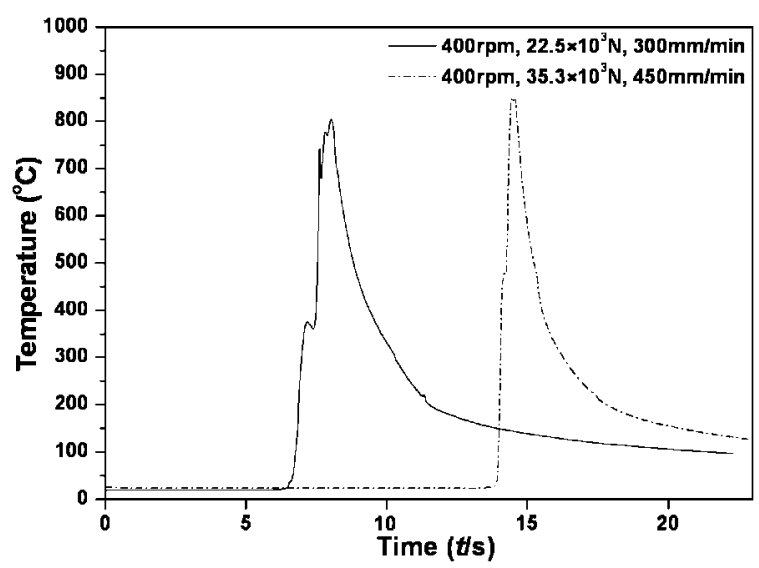

Fig. 5 Temperature hysteresis in the stir zone during the hybrid friction stir welding.
The grain boundary maps of the base material and stir zone are shown in Fig. 6. Prior to welding, the base material consisted of grains ranging in size from 2 to $25 \mu \mathrm{m}$, with an average grain size of $5.5 \mu \mathrm{m}$, as shown in Fig. 6(a). The application of HFSW led to grain refinement in the stir zone, and the grains were more refined at high welding speeds. As a result, the grain size in the stir zone of the specimen welded at $300 \mathrm{~mm} / \mathrm{min}$ ranged between $1 \mu \mathrm{m}$ and $15 \mu \mathrm{m}$ with an average grain size of $3.8 \mu \mathrm{m}$, as shown in Fig. 6(b), and the grains in the specimen welded at $450 \mathrm{~mm} / \mathrm{min}$ were more refined, with an average grain size of $3.2 \mu \mathrm{m}$, when compared to those in the specimen welded at $300 \mathrm{~mm} / \mathrm{min}$, as shown in Fig. 6(c).

The GBCDs of the base material and the welded specimen are shown in Fig. 7. More than $95 \%$ of the distribution in the

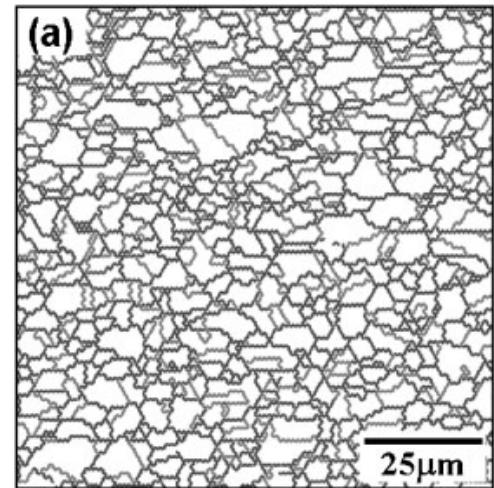

High angle boundary

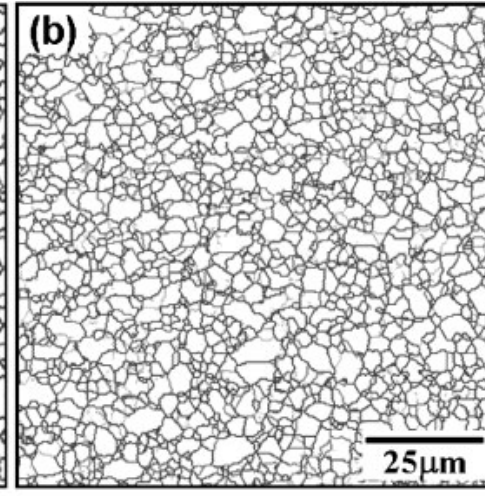

Low angle boundary

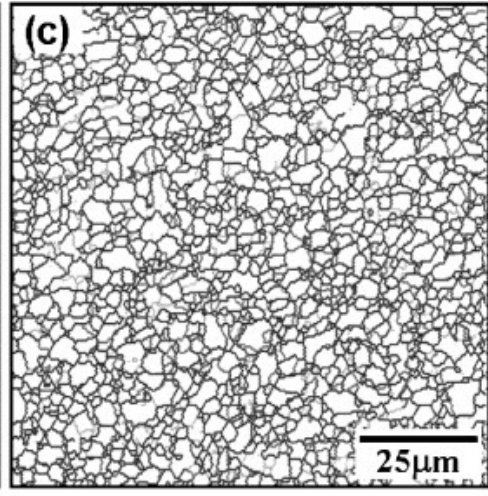

Annealing twin boundary

Fig. 6 Grain boundary maps of (a) base material and (b) specimen subjected to hybrid friction stir welding at a welding speed of $300 \mathrm{~mm} /$ min, and (c) specimen subjected to hybrid friction stir welding at a welding speed of $450 \mathrm{~mm} / \mathrm{min}$; gray, black, and red lines indicate lowangle boundary, high-angle boundary, and annealing twin boundary, respectively.
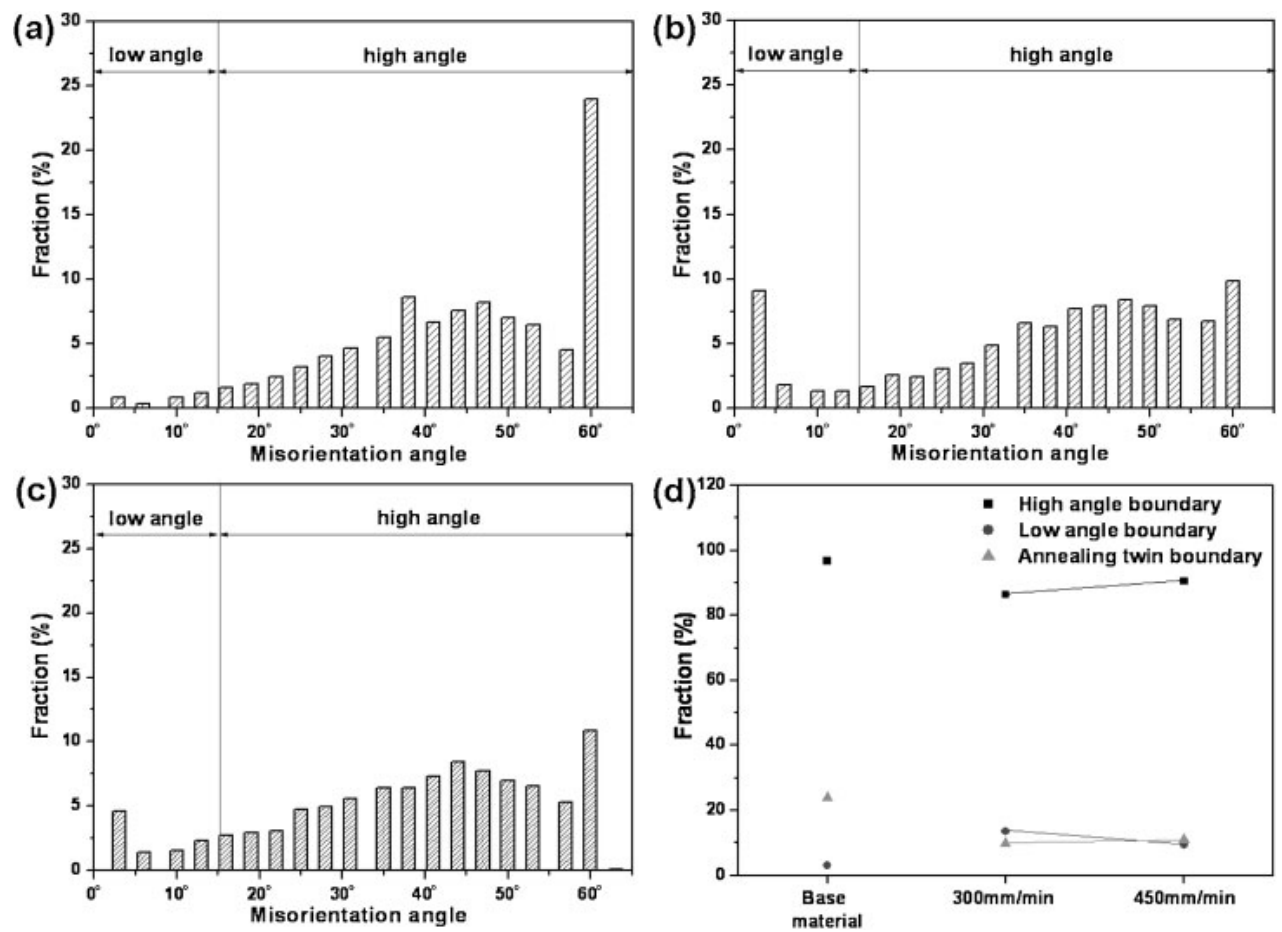

Fig. 7 Changes introduced in grain boundary character distribution by the hybrid friction stir welding; (a) base material, (b) specimen welded at a welding speed of $300 \mathrm{~mm} / \mathrm{min}$, (c) specimen welded at a welding speed of $450 \mathrm{~mm} / \mathrm{min}$, and (d) boundary fraction. 
(a)

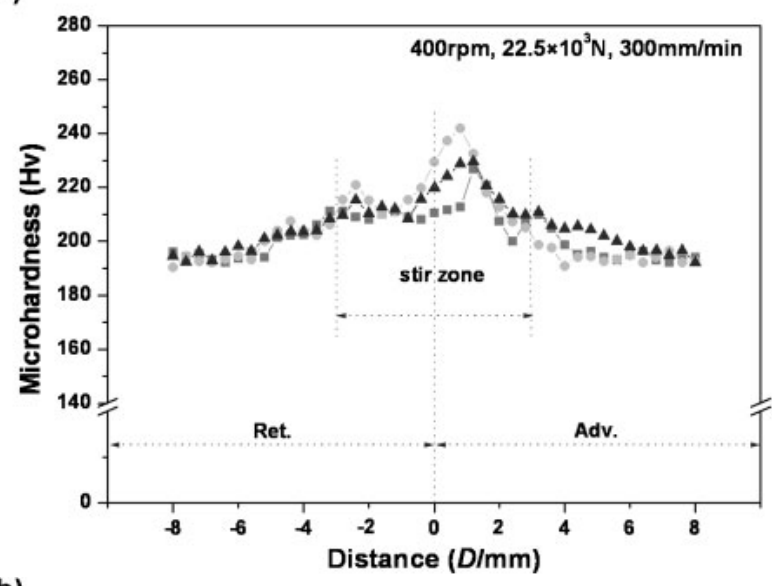

(b)

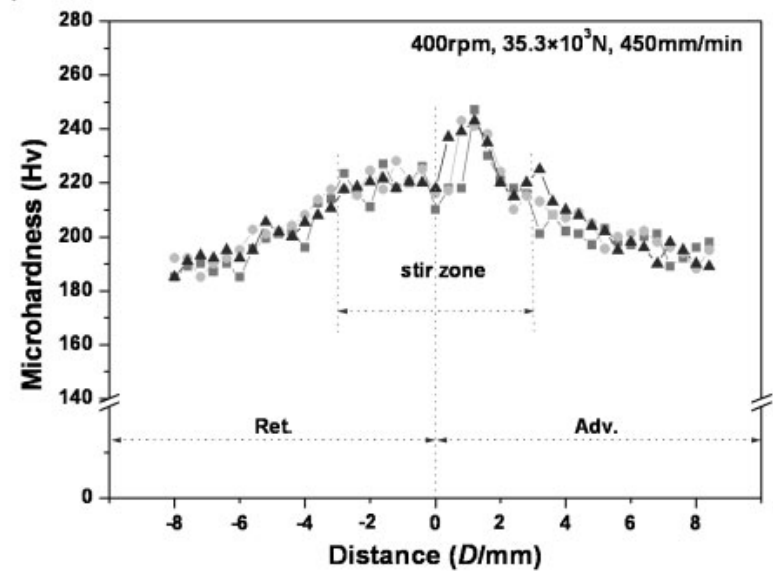

Fig. 8 Distributions of Vickers microhardness in hybrid friction stir welded specimens at a welding speed of (a) $300 \mathrm{~mm} / \mathrm{min}$ and (b) $450 \mathrm{~mm} /$ min. Adv. and Ret. Indicate the advancing side and retreating side, respectively, of the weld.

base material was composed of high-angle grain boundaries $\left(>15^{\circ}\right)$, as shown in Fig. 7(a), and more than $24 \%$ of the distribution was composed of $60^{\circ}$ in grain-boundary angles; these high-angle grain boundaries were identified by the presence of an annealing twin boundary, which is usually observed in fcc metals that have a low stacking-fault energy. More than $87 \%$ of the distribution in the specimen welded at $300 \mathrm{~mm} / \mathrm{min}$ was composed of high-angle grain boundaries, and $11 \%$ of the distribution was composed of annealing twin boundaries; the percentage of annealing twin boundaries in the welded specimen was less than that of the annealing twin boundaries in the base material, as shown in Fig. 7(b). More than $90 \%$ of the distribution in the specimen welded at $450 \mathrm{~mm} / \mathrm{min}$ was composed of high-angle grain boundaries, and $10 \%$ of the distribution was composed of annealing twin boundaries similar to those in the specimen welded at $300 \mathrm{~mm} / \mathrm{min}$, as shown in Fig. 7(c). Changes in grain boundary distributions with increasing welding speeds are shown in Fig. 7(d).

Microhardness distribution in the welded specimens is shown in Fig. 8. The Vickers microhardness of the base material ranged between $185 \sim 197 \mathrm{Hv}$, with an average microhardness of $192 \mathrm{Hv}$, as shown in Figs. 8(a) and (b). The Vickers microhardness at the stir zone of the specimen welded at $300 \mathrm{~mm} / \mathrm{min}$ was greater than that of the base
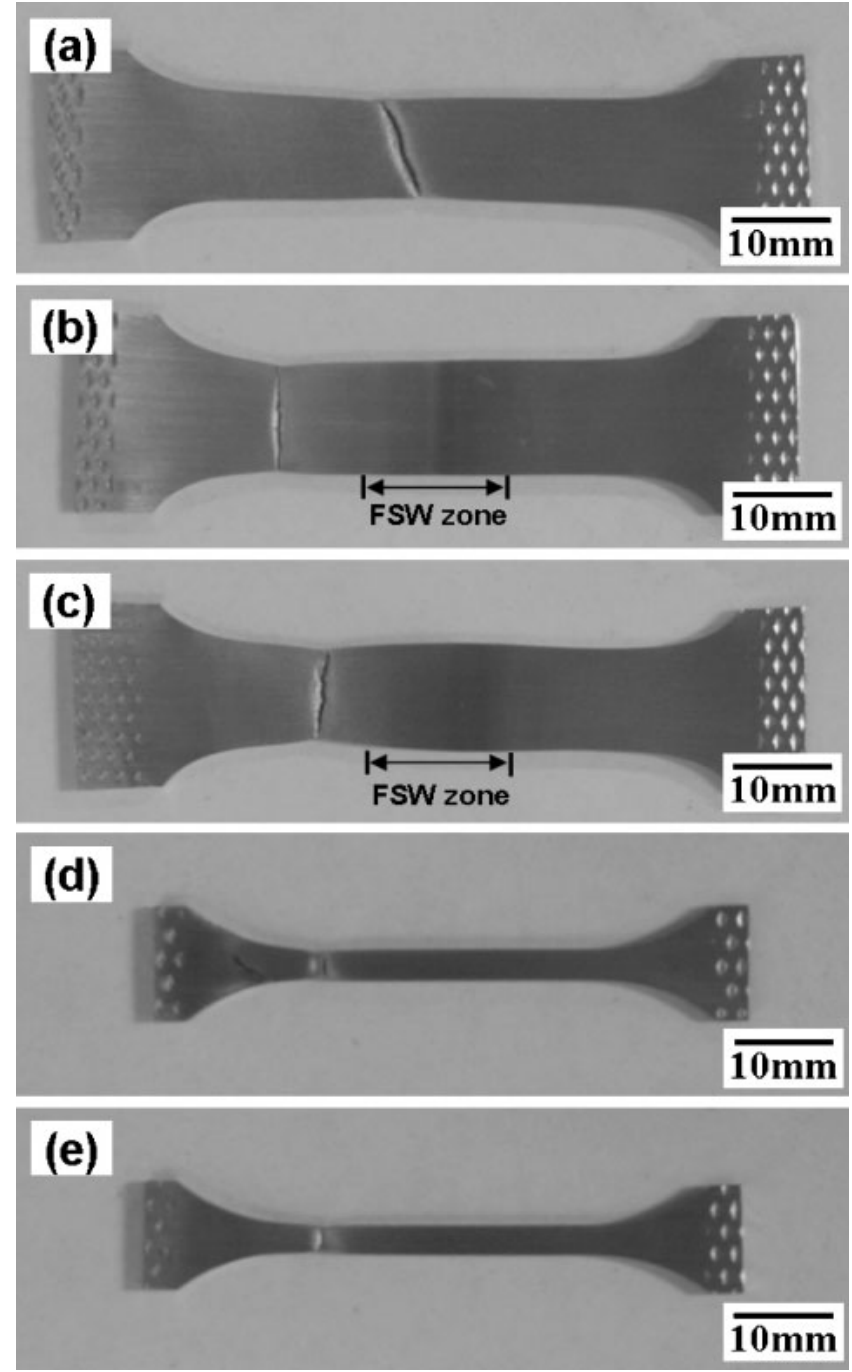

Fig. 9 Top views of the specimens subjected to the tensile tests. Transverse directions: (a) base material, (b) specimen welded at a welding speed of $300 \mathrm{~mm} / \mathrm{min}$ and (c) specimen welded at a welding speed of $450 \mathrm{~mm} / \mathrm{min}$. Longitudinal directions: (d) specimen welded at a welding speed of $300 \mathrm{~mm} / \mathrm{min}$ and (e) specimen welded at a welding speed of $450 \mathrm{~mm} / \mathrm{min}$.

material and ranged between $200 \sim 242 \mathrm{Hv}$, as shown in Fig. 8(a). The microhardness of the material increased with an increase in the welding speed; thus, the Vickers microhardness of the specimen welded at $450 \mathrm{~mm} / \mathrm{min}$ ranged between 210-250 Hv, as shown in Fig. 8(b).

The top views of the specimens subjected to the tensile tests are shown in Fig. 9. Under the tensile load, the base material elongated and broke along its center, as shown in Fig. 9(a). However, the HFSW joints welded at $300 \mathrm{~mm} / \mathrm{min}$ and $450 \mathrm{~mm} / \mathrm{min}$ were fractured at the base material, as shown in Figs. 9(b) and (c). The stir zone specimens were also elongated and broke, as shown in Figs. 9(d) and (e).

Results of the tensile tests on the hybrid friction stir welded specimens are shown in Fig. 10. The base material exhibited an ultimate tensile strength (UTS) of $698 \mathrm{MPa}$ and $38 \%$ elongation, as shown in Fig. 10. The increase in the welding speed led to a slight increase in UTS and to a decrease in elongation. As a result, the UTS along the transverse direction of the welded specimens were 718 and $728 \mathrm{MPa}$ at $300 \mathrm{~mm} / \mathrm{min}$ and $450 \mathrm{~mm} / \mathrm{min}$, respectively, and the 


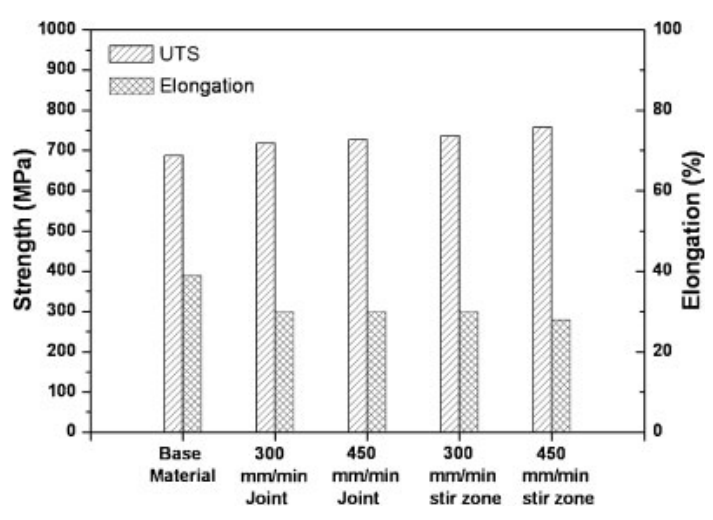

Fig. 10 Transverse (weld joint) and longitudinal (stir zone) tensile properties of hybrid friction stir welded specimens.

elongations were $30 \%$ under all conditions. The stir zone specimens exhibited an UTS of 736 and $758 \mathrm{MPa}$ at 300 $\mathrm{mm} / \mathrm{min}$ and $450 \mathrm{~mm} / \mathrm{min}$, respectively, which is significantly higher than the UTS of the base material, while the elongations were $30 \%$ and $28 \%$ at $300 \mathrm{~mm} / \mathrm{min}$ and 450 $\mathrm{mm} / \mathrm{min}$, respectively.

\section{Discussion}

\subsection{Effects of HFSW}

In the present study, the effects of HFSW, which employs a YAG laser as a preheating source, are observed. By applying conventional FSW at a rotation speed of $400 \mathrm{rpm}$ and a downward force of $22.5 \times 10^{3} \mathrm{~N}$ exerted by the tool on the material, the material was perfectly welded at a welding speed of $200 \mathrm{~mm} / \mathrm{min}$ without any defects in the weld zone. ${ }^{12)}$ However, the application of the preheating source was effective in increasing the welding speed. As a result, the material was welded at a speed of $300 \mathrm{~mm} / \mathrm{min}$, which is faster compared to that of the conventional FSW. This could have resulted from the decrease in frictional load between the material and the tool. In other words, by using a heat source during FSW, the axial downward force exerted by the tool on the material decreases due to the creation of a preheated zone by the YAG laser irradiation. As a result of this, it is easier to initiate plastic flow in HFSW when compared to conventional FSW. Therefore, the application of a heat source in FSW can effectively increase the welding speed without causing defects in the weld zone.

\subsection{Grain refinement}

The application of HFSW led to grain refinement, and the grains were more refined at higher welding speeds. As a result, the average grain size in the stir zone decreased from 3.8 to $3.2 \mu \mathrm{m}$ at $300 \mathrm{~mm} / \mathrm{min}$ and $450 \mathrm{~mm} / \mathrm{min}$, respectively; the grains in the stir zone were more refined than those in the base material $(5.5 \mu \mathrm{m})$, as shown in Fig. 6. This result shows that at the same rotation speed (and hence equal downward forces exerted by the tool), the grains in the material subjected to HFSW were more refined than those in the material subjected to conventional FSW $(4.4 \mu \mathrm{m}) .{ }^{12)}$ Grain refinement during HFSW can be explained by the dynamic recrystallization of the grains in the material. In other words, HFSW is accompanied by high strain rate (stored energy) and frictional heat between the material and the tool, and the strain rate increases by increasing the welding speed. Moreover, the distribution of peak temperature during HFSW was approximately $810^{\circ} \mathrm{C}$ and $845^{\circ} \mathrm{C}$ at $300 \mathrm{~mm} / \mathrm{min}$ and $450 \mathrm{~mm} / \mathrm{min}$, respectively. These temperatures were sufficient to recrystallize the grains of Inconel 600 , and the relative cooling rate was increased by increasing the welding speed, as shown in Fig. 5. Therefore, the high strain rate and sufficient heat input at high welding speeds can lead to effective dynamic recrystallization of the grains of the material, thereby resulting in a refined grain structure.

The material used in this study was Inconel 600, which is a fcc metal that has low stacking-fault energy. When compared to the materials with high stacking-fault energies, such as Al alloys, these materials can easily undergo dynamic recrystallization; however, it is difficult to rearrange the dislocation through dynamic recovery of the material. ${ }^{13,14)}$ In other words, during HFSW, these materials can form recrystallization nuclei more easily than the materials with high stacking-fault energies; the number of recrystallization nuclei formed can be increased by increasing the strain rate, which can be increased by increasing the welding speed. Therefore, the recrystallization nuclei can be formed simultaneously at the grains and the grain boundaries that have a high density of dislocations. As a result, the grains can be made more refined by increasing the welding speed.

\subsection{Improvement in mechanical properties}

Mechanical properties such as the microhardness and tensile strength of the material were increased by the application of HFSW. This can be explained by the grain refinement in the stir zone. The microhardness of the base material ranged between 185 195 HV; however, the microhardness of the stir zone ranged between $205 \sim 245 \mathrm{HV}$ at $300 \mathrm{~mm} / \mathrm{min}$ and $210 \sim 250 \mathrm{HV}$ at $450 \mathrm{~mm} / \mathrm{min}$; these values are much higher than the microhardness of the base material, as shown in Fig. 8. This increase in microhardness was caused by the grains in the stir zone, which were more refined $(3.8 \mu \mathrm{m}$ at $300 \mathrm{~mm} / \mathrm{min}$ and $3.2 \mu \mathrm{m}$ at $450 \mathrm{~mm} / \mathrm{min})$ when compared to the grains in the base material $(5.5 \mu \mathrm{m})$, as shown in Fig. 6. Hence, this study successfully proves the effect of grain size on the mechanical properties of the materials by showing that the microhardness of the materials can be increased by increasing the extent of grain refinement.

In the transverse tensile test of the joint, the base material first deformed and then broke, as shown in Fig. 9, which can also be explained by the grain size in the stir zone. The grains in the stir zone were more refined than those in the base material. As a result, the base material could be deformed and broken more easily when compared to the stir zone specimens. Moreover, while testing the longitudinal tensile strength of the stir zone specimens, the tensile strength of the specimens was increased by increasing the welding speed, which increased the extent of grain refinement, as shown in Fig. 10. Therefore, this test showed the effect of grain size on the tensile strength of the specimen. 


\section{Conclusions}

Hybrid friction stir welding can be successfully performed at welding speeds of 300 and $450 \mathrm{~mm} / \mathrm{min}$ by using a YAG laser as the preheating source without causing defects in the stir zone. Owing to the increase in the welding speed of HFSW, the average grain size in the base material $(5.5 \mu \mathrm{m})$ was decreased to $3.8 \mu \mathrm{m}(300 \mathrm{~mm} / \mathrm{min})$ and $3.2 \mu \mathrm{m}(450 \mathrm{~mm} / \mathrm{min})$ in the stir zone, accompanied by the dynamic recrystallization under all conditions. This grain refinement was effective in improving the mechanical properties, and as a result, the microhardness notably increased from $190 \mathrm{Hv}$ (in the base material) to $250 \mathrm{Hv}$ (in the stir zone) by increasing the welding speed. The tensile strength also increased from $698 \mathrm{MPa}$ (in the base material) to $758 \mathrm{MPa}$ (in the stir zone); it was observed that the base material broke under all joint conditions. Therefore, the application of HFSW by using YAG laser as the preheating source is effective in increasing the extent of grain refinement and improving the mechanical properties of Inconel 600 .

\section{Acknowledgements}

This work was supported by a Grant-in-Aid for Scientific
Research (A) from the Japan Society for the Promotion of Science (JSPS).

\section{REFERENCES}

1) G. S. Was: Corrosion 46 (1990) 319-330.

2) W. F. Smith: Structure and Properties of Engineering Alloys, (1981).

3) Welding Handbook: vol. 3, 8th ed., (AWS, Miami, FL, 1996), pp. 218288.

4) J. D. Kim, C. J. Kim and C. M. Chung: J. Mater. Process. Tech. 114 (2001) 51-56.

5) F. Ye, H. Fujii, T. Tsumura and K. Nakata: J. Mater. Sci. 41 (2006) 5376-5379.

6) Y. S. Sato, P. Arkom, H. Kokawa, T. W. Nelson and R. J. Steel: Mater. Sci. Eng. A 477 (2008) 250-258.

7) M. Gao, X. Zeng, Q. Hu and J. Yan: J. Mater. Process. Tech. 209 (2009) 785-791.

8) G. L. Liang, G. Zhou and S. Q. Yuan: Mater. Sci. Eng. A 499 (2009) 93-96.

9) L. M. Liu and X. Zhao: Mater. Char. 59 (2008) 1279-1284.

10) M. Gao, X. Zeng, J. Yan and Q. Hu: Appl. Surf. Sci. 254 (2008) 57155721.

11) H. Fujii, T. Tatsuno and T. Tsumura: Mater. Sci. For. 580-582 (2008) 393-396.

12) K. H. Song, H. Fujii and K. Nakata: Mater. Trans. 50 (2009) (in accepted).

13) J. M. Howe: Interfaces in Materials, (1997).

14) F. J. Humphreys and M. Hatherly: Recrystallization and Related Annealing Phenomena, 2nd ed., (Elsevier, Oxford, UK, 2004). 